\title{
Removal of bisphenol A (BPA) from biologically treated wastewater by microfiltration and nanofiltration
}

\author{
M. Zielińska ${ }^{1}$ - K. Bułkowska ${ }^{1}$ A. Cydzik-Kwiatkowska ${ }^{1} \cdot$ K. Bernat $^{1}$ • \\ I. Wojnowska-Baryła ${ }^{1}$
}

Received: 7 October 2015/Revised: 14 April 2016/Accepted: 27 June 2016/Published online: 12 July 2016

(c) The Author(s) 2016. This article is published with open access at Springerlink.com

\begin{abstract}
Bisphenol A (BPA) is an endocrine disruptor that is difficult to completely remove from wastewater by conventional biological methods. Increased post-treatment BPA removal with ceramic membranes is worth investigating because of these membranes' mechanical and chemical stability and lifespan. To determine the effectiveness of ceramic membranes for post-treatment of biologically treated BPA-contaminated wastewater, microfiltration (MF) and nanofiltration (NF) were conducted. Both processes removed BPA completely at an initial BPA concentration of $0.3 \pm 0.14 \mathrm{mg} / \mathrm{L}$. Increased concentration of $0.7 \pm 0.29 \mathrm{mg} / \mathrm{L}$ decreased BPA removal. MF removed at least $24 \%$ of BPA, presumably because BPA was adsorbed on particulate matter, which was retained by the membrane, or adsorbed on its surface. NF removed up to thrice more BPA. MF and NF completely removed suspended solids and 40-60\% COD. Filtration capacity decreased with time due to fouling but did not depend on initial BPA concentration. BPA concentrations in municipal wastewater are typically lower than the lowest concentration tested, where MF completely removed BPA. Hence, MF ceramic membranes appear a promising solution for post-treatment of BPA-containing wastewater. MF can be used at a much lower transmembrane pressure than $\mathrm{NF}$, requiring less energy to pump wastewater through the membrane, thus reducing costs.
\end{abstract}

M. Zielińska

magdalena.zielinska@uwm.edu.pl

1 Department of Environmental Biotechnology, University of Warmia and Mazury in Olsztyn, Słoneczna Str. 45G, 10-709 Olsztyn, Poland
Keywords Secondary effluent $\cdot$ Endocrine disrupting compound $\cdot$ Membrane filtration $\cdot$ Membrane fouling

\section{Introduction}

Bisphenol A (2,2-bis-4-hydroxyphenylpropane, BPA) is a widely used xeno-estrogen, mainly in the production of polycarbonate plastics and epoxy resins. It is considered an environmental pollutant with comparatively high biological activity and is classified as an endocrine disrupting compound (EDC). The most common source of BPA in natural water is wastewater. Although BPA can be degraded by microorganisms, it is hard to be completely removed from wastewater by conventional biological treatment methods. As a result, residual BPA is present in the effluents from municipal wastewater treatment plants in concentrations ranging from $0.01 \mu \mathrm{g} / \mathrm{L}$ (Nasu et al. 2001) to $86.0 \mu \mathrm{g} / \mathrm{L}$ (Kasprzyk-Hordern et al. 2009). This is a cause for concern because BPA is estrogenic at concentrations below $1 \mathrm{ng} / \mathrm{L}$ (Tanaka et al. 2000).

One of the reasons that biological treatment is not completely effective is because BPA can be sorbed on suspended solids or biofilm. BPA has a moderate affinity for the solid phase because it has an octanol-water coefficient $\left(\log K_{\text {ow }}\right.$ ) of 3.32 (Stringfellow and Alvarez-Cohen 1999). Thus, BPA can sorb to suspended solids that were not completely removed in a secondary clarifier. This makes post-treatment necessary to lower the concentration of BPA in effluent and limit its adverse effects on water ecosystems.

One of the options for post-treatment is membrane filtration, which produces high-quality effluents with low concentrations of organic compounds. BPA rejection by membranes ranges from $18 \%$ (Kimura et al. 2004) to 
$>99.9 \%$ (Agenson et al. 2003). This wide range of rejection rates is due to the fact that there is a strong relationship between rejection rate and membrane type; for phenolic compounds in particular, there is a linear relationship between rejection efficiency and molecular weight cut-off (Jung et al. 2007). For this reason, the rejection efficiency of EDCs, including BPA, decreases in the following order: reverse osmosis (RO), nanofiltration (NF), ultrafiltration (UF) and microfiltration (MF).

Among the various treatment options for EDC removal from solutions, NF and low-pressure techniques (MF and UF) are worth examining. NF requires high transmembrane pressure, which increases operating costs. However, it can separate organic micropollutants of low molecular weight and operate at pressures lower than RO. In contrast, although MF and UF are relatively less effective, they offer the advantage of operation at lower transmembrane pressures. This makes these processes worth investigating with the aim of improving their efficiency. So far, MF has been able to remove from 20 to $95 \%$ of BPA from drinking water; efficiency dropped as the membrane became saturated with BPA (Bing-zhi et al. 2010).

The use of only membrane filtration for wastewater purification is limited by the clogging of membranes with pollutants (Sun et al. 2015), which shortens the filtration cycle and lower membrane life. So called fouling accompanies membrane filtration and is caused by the presence of organic compounds in wastewater. This may affect the removal of low-molecular mass organic micropollutants. To delay the drop in removal efficiency and to lengthen membrane life, different hybrid processes can be used to remove BPA and other EDCs. These hybrid processes combine membrane filtration with BPA degradation during Fenton's process, among other techniques. However, significant membrane fouling was observed in the NF of the effluent even after Fenton oxidation (Escalona et al. 2014).

In the modules for BPA rejection, different types of membranes were used, particularly ones fabricated from organic materials such as polysulfone and polyamide (Nghiem et al. 2008), polyethylene (Chen et al. 2008) or polyvinylidenefluoride (Bing-zhi et al. 2010). However, there are few papers on the use of inorganic ceramic membranes that are characterized by good thermal and chemical stability, high pressure and mechanical resistance, long life and good antifouling properties.

Although BPA in biologically treated wastewater can be both adsorbed to particulate matter and present in soluble form, previous studies with membrane bioreactors have focused on removing only adsorbed BPA with MF and UF
(Zuehlke et al. 2003, Schröder 2006, Chen et al. 2008). The use of these membrane bioreactors had several drawbacks. To ensure high efficiency, these systems were operated at a high hydraulic retention time (HRT) of over $10 \mathrm{~h}$, or additional physicochemical processes were performed, such as ozonation of the permeate. In contrast to the above studies, NF would allow removal of both adsorbed and soluble BPA, but it is not known whether the use of NF would substantially increase the efficiency of BPA removal because the size of this increase would largely depend on the amount of BPA adsorbed to suspended solids. If most BPA is adsorbed to these solids, then MF could be sufficient for post-treatment because the MF filter can serve as a secondary clarifier and separate BPA sorbed on suspended solids from the secondary effluent. However, the relative removal efficiency of MF versus NF has not been investigated. Thus, we compared MF and NF ceramic membranes for the removal of BPA from effluent from reactors with immobilized biomass operated at an HRT of only 1.5 h. At such a short HRT, high concentrations of suspended solids in the effluent are observed, to which BPA and other hydrophobic compounds may be sorbed. Because high concentrations of solids can foul membranes, we tested the susceptibility of the ceramic membranes to fouling. These results will help to determine the most effective combination of membrane selectivity and permeability when using ceramic membranes for BPA removal from secondary effluent.

\section{Materials and methods}

\section{Characteristics of feed wastewater}

The experiments were run with biologically treated wastewater that contained BPA. The biological treatment system consisted of an aerobic up-flow reactor with biomass immobilized on a stationary porous support. This reactor treated synthetic wastewater, imitating municipal wastewater that was spiked with BPA at concentrations of 2.5, 5.0 and $10.0 \mathrm{mg} / \mathrm{L}$ (Zielińska et al. 2014). The volumetric loading rate was $7 \mathrm{~kg} \mathrm{COD} /\left(\mathrm{m}^{3} \mathrm{~d}\right)$, and the organic compounds-to-nitrogen ratio $(\mathrm{COD} / \mathrm{N})$ was 7.2 . Due to the very short hydraulic retention time in the bioreactor of $1.5 \mathrm{~h}$, this effluent had concentrations of suspended solids of $78 \pm 12 \mathrm{mg}$ TSS/L and concentrations of COD of $212 \pm 36 \mathrm{mg} / \mathrm{L}$. Concentrations of BPA were $0.3 \pm 0.14$, $0.5 \pm 0.19$ and $0.7 \pm 0.29 \mathrm{mg} / \mathrm{L}$, respectively at the initial BPA concentrations in synthetic wastewater of 2.5, 5.0 and 


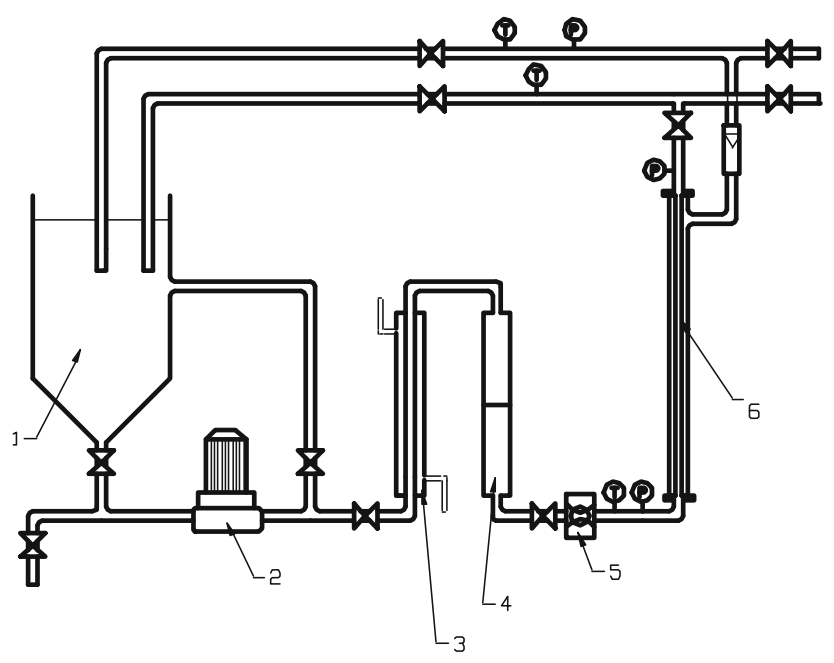

Fig. 1 Schematic of the membrane installation: 1 process tank, 2 pump, 3 heat exchanger, 4 prefilter, 5 flow control, 6 membrane module, $T$ thermometer, $P$ manometer

$10.0 \mathrm{mg} / \mathrm{L}$. The overall efficiency of the bioreactor ranged from 61 to $66 \%$ COD removal and from 87 to $92 \%$ BPA removal.

\section{Membrane installation}

The experiments on membrane filtration of wastewater were conducted in an installation that consisted of a $10-\mathrm{L}$ feed tank, a high-pressure pump (CRN(E), Grundfos), a membrane module placed outside the feed tank, a flowmeter, a heat exchanger, a 1-mm prefilter, pressure gauges at the inlet and outlet of the membrane module, a recycling line to recirculate retentate back to the feed tank and a line to receive permeate from the system (Fig. 1). The membrane module housed one Inside-Céram ${ }^{\mathrm{TM}}$ tubular asymmetric ceramic membrane (Tami Industries). This membrane was made from a mixture of $\mathrm{TiO}_{2}$ and $\mathrm{ZrO}_{2}$. The membrane was $300 \mathrm{~mm}$ long with an external diameter of $25 \mathrm{~mm}$. There were 23 channels inside the membrane. Each channel had a hydraulic diameter of $3.5 \mathrm{~mm}$. According to the manufacturer, the total effective filtration area was $0.1 \mathrm{~m}^{2}$ and the specific area was $680 \mathrm{~m}^{2} / \mathrm{m}^{3}$. The installation worked under cross-flow conditions. The feed solution was pumped into the membrane channels, and the permeate came out from the external membrane walls. To limit membrane clogging, backwashing was periodically done after each filtration cycle, using washing agents recommended by the manufacturer.

\section{Membrane filtration protocol}

The membrane installation was operated in two variants. In the first variant, an MF membrane was placed in the membrane module. In this setup, the membrane functioned as a secondary clarifier. In the second variant, an $\mathrm{NF}$ membrane was used in the membrane module to remove soluble and adsorbed pollutants.

Before filtration, the membrane module was flushed by circulating distilled water for $20 \mathrm{~min}$. After that, pure water permeation was measured. The average permeation flux of distilled water $\left(J_{\mathrm{W}}\right)$ was $1500 \mathrm{~L} /\left(\mathrm{m}^{2} \mathrm{~h}\right)$ for the MF membrane and $80 \mathrm{~L} /\left(\mathrm{m}^{2} \mathrm{~h}\right)$ for the $\mathrm{NF}$ membrane. Filtrations were performed with a feed flow velocity of 22-29 L/min and a temperature of $21^{\circ} \mathrm{C}$. The initial transmembrane pressure (TMP) (i.e., the difference in pressure between feed and filtrate) was 0.3 MPa for MF and 0.7 MPa for NF. Turbulent flow in the membrane channels lowered concentration polarization.

To determine the effect of BPA concentrations on filtration by both MF and NF membranes, biologically treated wastewater with different concentrations of BPA was used. In series 1 (S1), BPA concentration in the feed solution was $0.3 \pm 0.14 \mathrm{mg} / \mathrm{L}$; in series $2(\mathrm{~S} 2)$, it was $0.5 \pm 0.19 \mathrm{mg} / \mathrm{L}$; in series $3(\mathrm{~S} 3), 0.7 \pm 0.29 \mathrm{mg} / \mathrm{L}$. During filtration, permeation tests were conducted. The time necessary to collect half a liter of permeate was measured. These measurements were taken until the membrane was totally clogged. At the end of each filtration experiment, the membranes were rinsed with distilled water.

Based on the permeation tests, the transport properties of membranes were calculated, including permeate flux (filtration rate) $\left(J_{\mathrm{V}}\right.$, Eq. 1) and BPA flow through the membrane ( $d_{\mathrm{BPA}}$, Eq. 2):

$J_{\mathrm{V}}=\frac{V_{\mathrm{P}}}{t \times A} \quad\left(\mathrm{~L} /\left(\mathrm{m}^{2} \mathrm{~h}\right)\right)$,

$d_{\mathrm{BPA}}=J_{\mathrm{V}} \times C_{\mathrm{P}} \quad\left(\mathrm{mg} /\left(\mathrm{m}^{2} \mathrm{~h}\right)\right)$.

The efficiency of membrane filtration was determined based on the recovery value, i.e., the fraction of the feed flow which passes through the membrane ( $Y$, Eq. 3$)$, on the volume concentration factor (VCF, Eq. 4) and on total membrane resistance ( $R_{\mathrm{m}}$, Eq. 5$)$ :

$Y=\frac{V_{\mathrm{P}}}{V_{\mathrm{F}}} \times 100(\%)$,

$\mathrm{VCF}=\frac{V_{\mathrm{F}}}{V_{\mathrm{F}}-V_{\mathrm{P}}} \quad(-)$, 
$R_{\mathrm{m}}=\frac{\mathrm{TMP}}{J_{\mathrm{V}}} \quad((\mathrm{MPa} \mathrm{s}) / \mathrm{m})$.

The separation properties of the membranes were estimated based on the percentage of rejection $\left(R_{\mathrm{BPA}}\right.$, Eq. 6):

$R_{\mathrm{BPA}}=\left(1-\frac{C_{\mathrm{P}}}{C_{\mathrm{F}}}\right) \times 100$

The sorption abilities of membranes were estimated based on the adsorption capacity (Ads, Eq. 7):

Ads $=\left(1-\frac{C_{\mathrm{R}} V_{\mathrm{R}}+C_{\mathrm{P}} V_{\mathrm{P}}}{C_{\mathrm{F}} V_{\mathrm{F}}}\right) \times 100$.

The fouling intensity was determined by calculating the normalised permeate flux $(\alpha)$, defined as the ratio of permeate flux $\left(J_{\mathrm{V}}\right)$ to the flux of distilled water $\left(J_{\mathrm{W}}\right)$. An $\alpha$ ratio near 1 indicates that the wastewater tends to clog the membrane very little, whereas a ratio near 0 indicates that it tends to clog the membrane quickly.

The abbreviations used in the equations are as follows: $A$-membrane filtration area $\left(\mathrm{m}^{2}\right), C_{\mathrm{F}}-\mathrm{BPA}$ concentration in the feed solution $(\mathrm{mg} / \mathrm{L}), C_{\mathrm{P}}-\mathrm{BPA}$ concentration in the permeate $(\mathrm{mg} / \mathrm{L}), C_{\mathrm{R}}-\mathrm{BPA}$ concentration in the retentate $(\mathrm{mg} / \mathrm{L}), t$-time for collecting a known volume of permeate (h), TMP - transmembrane pressure (MPa), $V_{\mathrm{F}}$-initial feed volume $(\mathrm{L}), V_{\mathrm{P}}$-total withdrawn permeate volume $(\mathrm{L}), V_{\mathrm{R}}$-retentate volume (L).

\section{Analytical methods}

In order to characterize the feed solution, the permeate and the retentate, their basic physicochemical descriptors were determined, including organic compounds as COD and $\mathrm{BOD}_{5}$, total suspended solids (TSS) and volatile suspended solids (VSS), according to APHA (1992).

BPA concentrations were determined in the feed solution, the permeate and the retentate. To prepare the samples for HPLC, solid-phase extraction (SPE) was performed, using Supelclean $^{\mathrm{TM}}$ ENVI $^{\mathrm{TM}}-18$ SPE$/ 3 \mathrm{~mL} / 500 \mathrm{mg}$ columns (Supelco). Before extraction, columns were treated with $8 \mathrm{~mL}$ methanol and $8 \mathrm{~mL}$ distilled water. To remove BPA from the solid particles in the samples, retentate samples were pretreated before SPE enrichment. For this pretreatment, a solution was prepared with retentate and methanol in a 3:1 ratio $(\mathrm{v} / \mathrm{v})$, and then shaken for $2 \mathrm{~h}$ at $150 \mathrm{rpm}$ before filtering. After filtration, the samples were added to the SPE columns. Columns have been dried under vacuum. Samples were eluted five times with $1 \mathrm{~mL}$ of acetonitrile, and then the acetonitrile was evaporated under a nitrogen stream to a volume of $2 \mathrm{~mL}$. Finally, $1 \mathrm{~mL}$ of sample was analyzed by HPLC. This analysis was performed with a Supelcosil LCPAH column from Supelco (5 $\mu \mathrm{m}$ particles, $4.6,150 \mathrm{~mm})$ using a Varian HPLC system with a UV-Vis detector at $278 \mathrm{~nm}$. The mobile phase (acetonitrile/water $=70 / 30, \mathrm{v} / \mathrm{v}$ ) was pumped at a flow rate of $1 \mathrm{~mL} / \mathrm{min}$. The temperature of the column oven was set at $35{ }^{\circ} \mathrm{C}$.

\section{Statistical analyses}

The normality of the distribution was tested with ShapiroWilk's test. The differences between the mean values derived from particular groups were examined with ANOVA and Tukey's test. The strength of the relationships between groups of results was determined using Pearson's correlation coefficient $(R)$. With all statistical analyses, $p \leq 0.05$ was considered significant. Statistica 9.0 PL (StatSoft) was used.

\section{Results and discussion}

\section{BPA removal by the MF and NF}

In this study, the effluent from the reactor with immobilized biomass was post-treated by membrane filtration because of high concentrations of COD, suspended solids and BPA. Two kinds of filtration were selected to differentiate the amount of BPA adsorbed on suspended solids, which would be removed by MF, and the amount of BPA in soluble forms, which would be removed by NF in addition to the BPA adsorbed on suspended solids.

At a BPA concentration in the feed solution of $0.3 \pm 0.14 \mathrm{mg} / \mathrm{L}$ (S1), BPA was completely removed with both MF and NF. In other words, there was no BPA flow through the membrane $\left(d_{\mathrm{BPA}}=0\right)$ (Fig. 2). In contrast, at higher BPA concentrations, removal of BPA decreased significantly and the NF membrane removed more BPA than the MF membrane. At an influent concentration of $0.5 \pm 0.19 \mathrm{mg} / \mathrm{L}$, BPA removal increased significantly from $24.2 \pm 5.8 \%$ during MF (MF_S2) to $75.0 \pm 7.2 \%$ during NF (NF_S2) (Tukey's test, $t=0.004, p<0.05$ ); $d_{\text {BPA }}$ decreased from 0.46 to $0.11 \mathrm{mg} /\left(\mathrm{m}^{2} \mathrm{~min}\right)$. This gave BPA concentrations in the permeate that averaged $379 \pm 113 \mu \mathrm{g} / \mathrm{L}$ after MF and $125 \pm 42 \mu \mathrm{g} / \mathrm{L}$ after NF. At an influent concentration of $0.7 \pm 0.29 \mathrm{mg} / \mathrm{L}$, BPA removal increased significantly from $37.4 \pm 4.3 \%$ during 


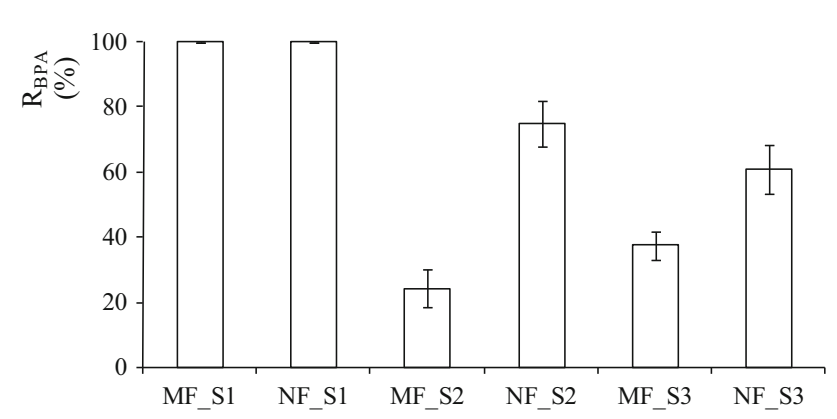

Fig. 2 BPA removal $\left(R_{\mathrm{BPA}}\right)$ by $\mathrm{MF}$ and $\mathrm{NF} \quad(\mathrm{S} 1-0.3 \pm$ $0.14 \mathrm{mg} \mathrm{BPA} / \mathrm{L}, \quad \mathrm{S} 2-0.5 \pm 0.19 \mathrm{mg} \mathrm{BPA} / \mathrm{L}, \quad \mathrm{S} 3-0.7 \pm 0.29$ $\mathrm{mg} \mathrm{BPA} / \mathrm{L})$

MF (MF_S3) to $61.0 \pm 7.5 \%$ during NF (NF_S3) (Tukey's test, $t=0.003, p<0.05$ ), which gave a decrease in $d_{\mathrm{BPA}}$ from 0.12 to $0.08 \mathrm{mg} /\left(\mathrm{m}^{2} \mathrm{~min}\right)$. BPA concentrations in the permeate were $438 \pm 229 \mu \mathrm{g} / \mathrm{L}$ after $\mathrm{MF}$ and $273 \pm 101 \mu \mathrm{g} / \mathrm{L}$ after NF.

For a given BPA concentration in the feed solution, characteristics of wastewater pumped into $\mathrm{MF}$ and $\mathrm{NF}$ installations were the same. In S2 and S3, BPA removal was higher with NF than with MF due to several factors. In general, the size exclusion is considered the dominant mechanism for rejection of large organic compounds, such as BPA. Electrostatic repulsion is negligible, as the other mechanism contributes to BPA removal, due to the nonionic form of this pollutant in neutral $\mathrm{pH}$ (Bolong et al. 2010). Size exclusion was a probable mechanism for BPA rejection with NF because the molecular mass of BPA (228.29 $\mathrm{g}$ ) is higher than the cut-off of this membrane. Weaker removal of BPA by MF than by NF showed that the MF membrane is too open for BPA; the pore size of the membrane is several orders of magnitude larger than the size of the BPA molecule. Higher removal with NF also indicates that part of the BPA or its byproducts were present in the liquid phase. In addition, the higher transmembrane pressure in NF ( $0.7 \mathrm{MPa})$ than in MF (0.3 MPa) increased the removal of BPA because the higher pressure increased the rate of water transport through the membrane, and in consequence, lowered BPA concentration in the permeate. Because BPA removal with MF was above $24 \%$, it might be expected that some of the BPA that was present in the feed solution was bound by particulate organic matter in the wastewater and allowed BPA to be separated by this membrane. Therefore, it can be stated that the presence of organic matter significantly improves EDC rejection by membranes (Jin and Hu 2015).
To calculate the mass balance, BPA loadings in the feed solution, permeate and retentate were measured. These calculations showed that real BPA loading in the retentate was 5-15\% lower than theoretical loadings, which indicates that BPA removal may be attributed to BPA adsorption on the membrane surface. Adsorption on the surface and in the inside structure of membranes is known to play a significant role in filtration for removal of hydrophobic compounds, such as BPA (Bing-zhi et al. 2010). On the membranes, there are many available sites for adsorption at the beginning of filtration, which allows greater adsorption of BPA, resulting in higher BPA removal. As filtration progresses, the membrane becomes saturated, resulting in higher BPA concentration in the permeate. In the present study, adsorption increased up to the moment of saturation of the membrane surface, as can be concluded from Fig. 2, which shows that when BPA concentration in the feed solution was increased, the removal percentage became lower. Similarly, in the experiment by Bolong et al. (2010), there was a significant decrease of BPA rejection from 60 to $30 \%$ when the initial BPA concentration was increased from 100 to $500 \mathrm{ppm}$. Another study has also found that, during NF of BPA solutions, rejection is related to a size exclusion mechanism and the ability of the membrane to adsorb BPA (Escalona et al. 2014). It has been suggested that physical adsorption on MF membranes is insignificant in pollutant removal because sorption is reversible and there is a limited active surface on the membrane with a limited number of sorption sites (Sun et al. 2015). However, our findings agree with those of Seyhi et al. (2012), because they indicate that sorption of BPA on the membrane or in its structure contributes considerably to BPA removal. In both variants (MF and NF) of our study, adsorption was shown by an increase in BPA concentration in the permeate when the concentration of BPA in the feed solution increased. In the present study, BPA adsorption on the MF membrane correlated linearly with BPA removal (Fig. 3), which indicates that BPA retention depended mainly on its adsorption on the membrane and in its structure. The large pore size in relation to the molecular size of BPA confirms that partial BPA removal may have been driven by adsorption on the membrane. Although adsorption on a membrane after biological treatment improves rejection of pollutants, with this process there is a risk of release of adsorbed organic micropollutants. 


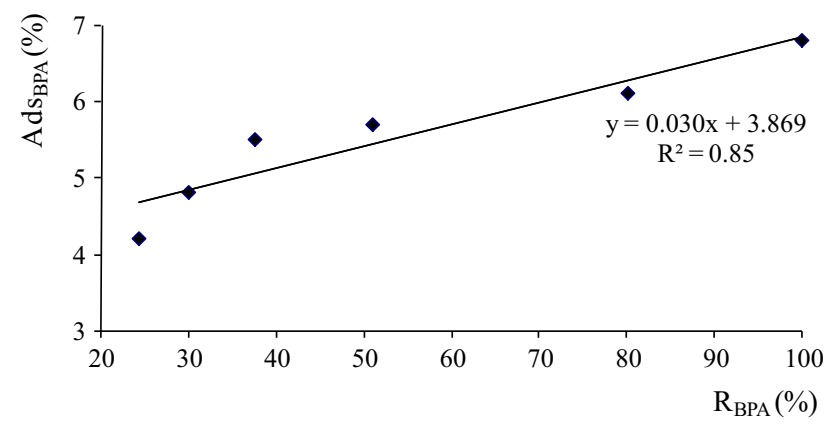

Fig. 3 BPA removal $\left(R_{\mathrm{BPA}}\right)$ versus BPA adsorption on membrane $\left(\mathrm{Ads}_{\mathrm{BPA}}\right)$ in $\mathrm{MF}$

\section{Suspended solids and COD removal by the MF and NF}

Suspended solids were present in the feed solutions in concentrations of $78 \pm 12 \mathrm{mg} \mathrm{TSS} / \mathrm{L}$; these solids were completely removed by MF and NF membranes. COD concentration in the feed solutions was $212 \pm 36 \mathrm{mg} / \mathrm{L}$. The experimental series did not differ significantly in terms of concentration of suspended solids and of COD in the feed solution. COD retention on the membranes ranged from 40 to $60 \%$, independently of the membrane type and the composition of the feed solution. The majority of COD retained on the membranes were in particulate form or were adsorbed on the bio-floc, hence COD removal by NF, which did not exceed $60 \%$, was similar to that by MF, and the differences between the two were not significant. This probably indicates that in the biological effluent, hard-todegrade organic compounds that were present in soluble forms had molecular masses lower than the cut-off of the membranes. The presence of these hard-to degrade compounds, which probably included the by-products of BPA metabolism, was indicated by a BOD/COD ratio lower than 0.1 . It is possible that the total efficiency of the removal of organic compounds could have been affected by extracellular polymeric substances being released from biological solids to the liquid because of shearing forces caused by the high-pressure pump or by particles in wastewater becoming fragmented by these forces. However, extracellular polymeric substances have a molecular mass in the range of 31.0-97.4 kDa (Zhang et al. 2007), so they would have been present only in the MF permeate. On the other hand, the fouling layer forming on the membrane surface, as an inherent phenomenon during membrane filtration, can potentially improve the separation on membranes, giving similar results for two different membranes.

\section{Hydraulic parameters of the MF and NF}

In hybrid treatment systems, the effluent from the biological reactor contains a mixture of active biomass, organic matter and inorganic compounds that may cause the loss of membrane capacity over time. In the current study, permeation tests showed that during both MF and NF the permeate flux $\left(J_{\mathrm{V}}\right)$ suddenly decreased at the beginning of the process. The flux then became stable until the flow stopped (Fig. 4; the final point in this figure was determined just before the permeate stopped flowing). The stoppage was due to clogging of the membrane by pollutants present in the feed solution. When this occurred, the membranes were washed.

The value of $J_{\mathrm{V}}$ was the lowest for MF and NF in S1, with the lowest BPA concentration in the feed solution, whereas $J_{\mathrm{V}}$ was the highest in S2 (Table 1). This indicates that BPA concentration did not affect $J_{\mathrm{V}}$. In S1 and S3, however, $J_{\mathrm{V}}$ was higher with NF, in which the filtration cycle was shorter than during MF. The filtration cycle was the longest in $\mathrm{S} 1$; in $\mathrm{S} 2$ and $\mathrm{S} 3$ it was significantly shorter (Tukey's test, $t=0.015, p<0.05$ ), but there were no correlations between BPA concentration in the feed solution and the length of filtration.

Based on the presented results, it cannot be said that membrane cut-off is the main factor that affects the length of the filtration cycle and permeate flux. Jin et al. (2010) have reported that the flux through a ceramic membrane with pores as small as $80 \mathrm{~nm}$ and a smooth surface had a longer filtration cycle than flux through a membrane with pore sizes of $300 \mathrm{~nm}$ and an irregular surface. In the current study, the structures of the membrane surfaces were not determined. The values of $J_{\mathrm{V}}$ were close for MF and NF (Fig. 4; Table 1). This may have been connected with the applied TMP (in the experiments, TMP values typical for particular membrane processes were used: $0.3 \mathrm{MPa}$ for MF and 0.7 MPa for NF). Generally, the increase in TMP causes an increase in flux values, based on Darcy's law. However, an increase in TMP could also be attributed to membrane fouling that results from concentration polarization (Sun et al. 2015). As the TMP increases, more pollutants accumulate on the membrane surface, and they form a gel layer and some pores are clogged. This increases filtration resistance and decreases the flux.

In the present study, the permeate flux decreased more with wastewater containing BPA than with distilled water. The normalised permeate flux $(\alpha)$ was significantly higher during NF than during MF (Table 1). When $\alpha$ is below 1, this indicates that the membrane is being fouled by organic 


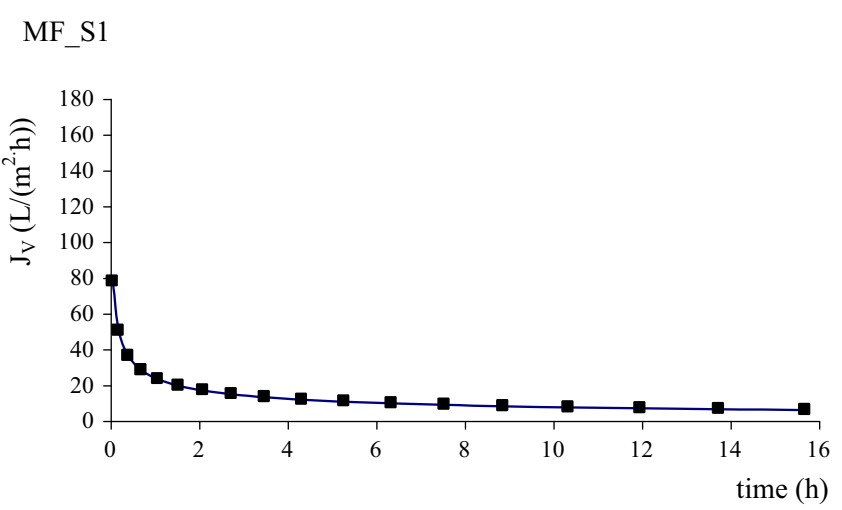

$$
\text { NF_S1 }
$$
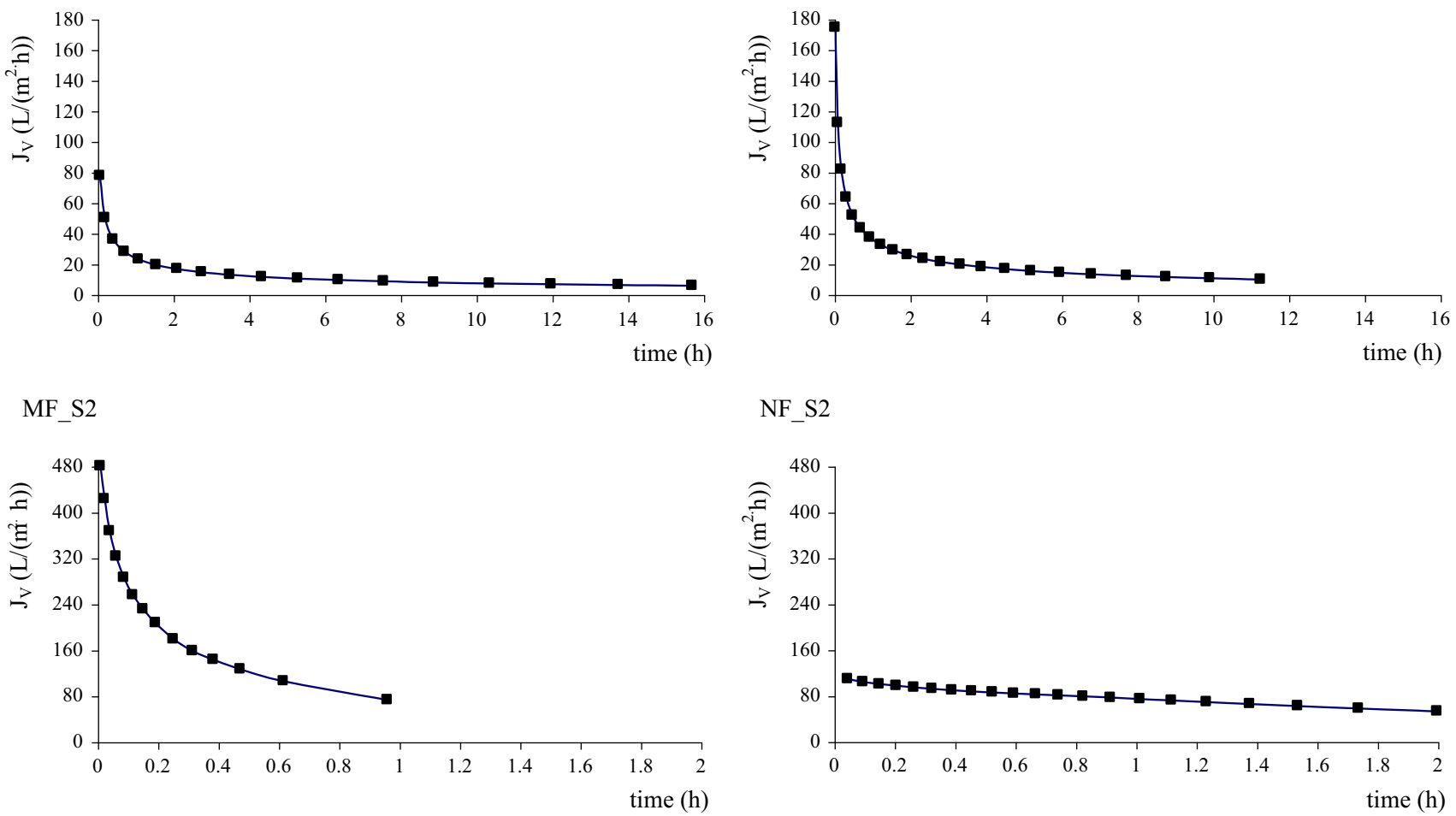

MF_S3

$$
\text { NF_S3 }
$$
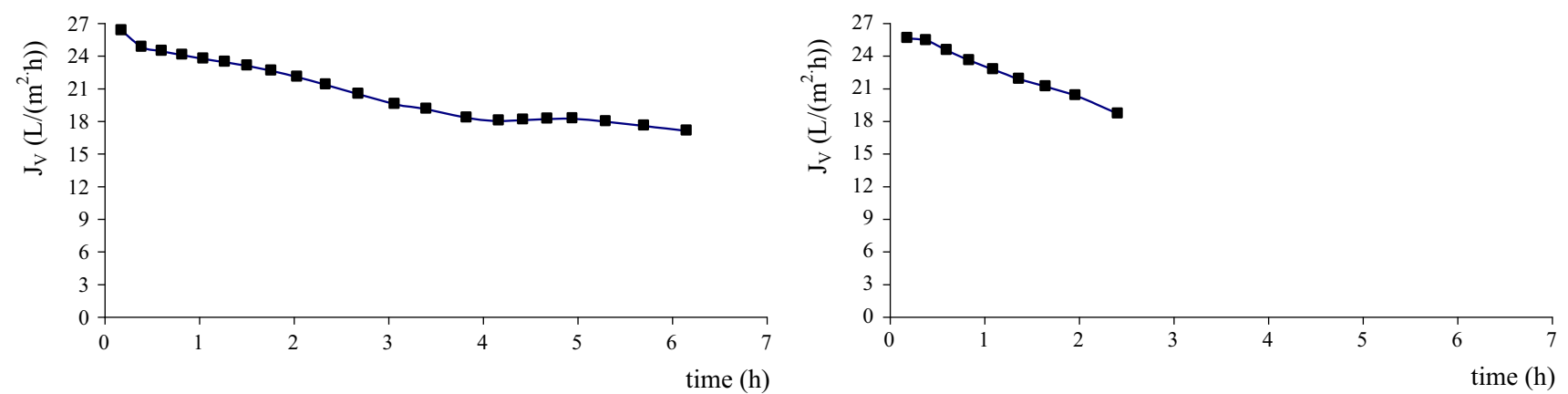

Fig. 4 Changes in permeate flux $\left(J_{\mathrm{V}}\right)$ with time during $\mathrm{MF}$ and $\mathrm{NF}$ at a BPA initial concentration of $0.3 \pm 0.14 \mathrm{mg} \mathrm{BPA} / \mathrm{L}$ (S1), $0.5 \pm 0.19 \mathrm{mg} \mathrm{BPA} / \mathrm{L}(\mathrm{S} 2)$ and $0.7 \pm 0.29 \mathrm{mg} \mathrm{BPA} / \mathrm{L}(\mathrm{S} 3)$

matter accumulating in the pores and on the surface of the membrane, which clogs the flux. This occurred with both MF and NF; however, $\alpha$ was close to 0 with MF, indicating that this membrane tended to become fouled more quickly than the NF membrane. The suggested reason is the ratio between pore size and size of the particles that determines membrane clogging. Particles close to or smaller than the diameter of the membrane pores foul the pores and membrane surfaces and form a filtration cake more quickly and to a greater extent than larger particles. Therefore, in MF, the flux decline is due to the pore clogging with compounds of a size similar to the pore diameter and due to cake formation with larger particles. On the other hand, dissolved compounds are more problematic in relation to fouling of NF membranes (Zahrim et al. 2011). Opinions differ about reasons for fouling. It may be caused mainly 
Table 1 Hydraulic parameters of $\mathrm{MF}$ and NF at BPA initial concentrations of $0.3 \pm 0.14 \mathrm{mg}$ BPA/L, $0.5 \pm 0.19 \mathrm{mg} \mathrm{BPA} / \mathrm{L}$ and $0.7 \pm 0.29 \mathrm{mg} \mathrm{BPA} / \mathrm{L}$

\begin{tabular}{llllllr}
\hline BPA conc. in the feed solution $(\mathrm{mg} / \mathrm{L})$ & Process & $J_{\mathrm{V}}\left(\mathrm{L} /\left(\mathrm{m}^{2} \mathrm{~h}\right)\right)$ & $\alpha(-)$ & $R_{\mathrm{m}}((\mathrm{MPa} \mathrm{s}) / \mathrm{m})$ & $Y(\%)$ & $\mathrm{VCF}(-)$ \\
\hline $0.3 \pm 0.14$ & $\mathrm{MF}$ & 6.0 & 0.004 & 179,641 & 75.0 & 4.0 \\
& $\mathrm{NF}$ & 9.6 & 0.120 & 262,172 & 91.7 & 12.0 \\
$0.5 \pm 0.19$ & $\mathrm{MF}$ & 72.6 & 0.050 & 14,851 & 58.3 & 2.4 \\
& $\mathrm{NF}$ & 52.8 & 0.600 & 47,619 & 87.5 \\
$0.7 \pm 0.29$ & $\mathrm{MF}$ & 16.8 & 0.010 & 64,240 & 8.0 \\
& $\mathrm{NF}$ & 18.6 & 0.230 & 135,397 & 65.6 & 37.5 \\
\hline
\end{tabular}

by relatively large colloids and soluble organic compounds ranging from 0.450 to $0.026 \mu \mathrm{m}$ (Zheng et al. 2009) or by extracellular polymers excreted by bacteria (Lee et al. 2006). Hydrophobic compounds, such as BPA, tend to strongly bind to hydrophobic materials like membranes. Hence, adsorption of organic compounds could change the hydrophobicity of the membrane surface, which could cause fouling (Escalona et al. 2014). In the current study, the intensity of fouling was probably not affected by COD in the feed solution, as indicated by the fact that the permeability of the membrane to COD was similar in MF and NF. In our study the concentration of colloidal organics, which are particles smaller than suspended solids, was not measured, though they may have caused fouling. Colloids that are deposited on the membrane may additionally adsorb dissolved organic compounds, which affect the rejection of micropollutants (Andrade et al. 2014).

Although the permeate flux differed in the various series, this was not due to different concentrations of suspended solids in the feed solution because these concentrations did not differ significantly. Similarly, Muthukumaran et al. (2011) found that the permeate flux was not influenced by changes in the concentrations of suspended solids in biologically treated effluent, which ranged from 13 to $30 \mathrm{mg} / \mathrm{L}$. Bendick et al. (2005) did find that the permeate flux decreased when the concentration of suspended solids in the feed solution increased from 56 to $239 \mathrm{mg} / \mathrm{L}$, but further increase did not change this parameter. Independent of the reason, fouling decreases the permeate flux, shortens the filtration cycle and destabilizes membrane function. These problems increase the operational cost of a membrane module.

In the series with the lowest initial BPA concentration in the present study, the permeate flux was also the lowest in both MF and NF. The low permeate flux was due to fouling; however, the fouling probably explains the complete retention of BPA in this series. When the membrane is clean at the beginning of filtration, the rejection of pollutants is determined by the nominal pore size. When fouling occurs during filtration, particles present in the wastewater clog membrane pores and form filtration cake. This decreases the filtration flux rate while simultaneously improving retention of pollutants. The rejection of particles smaller than the membrane cut-off is possible because fouling lowers the nominal diameter to the so-called effective diameter. This has been confirmed by Muthukumaran et al. (2011), who showed that fouling affects permeate flux more than pore size. Also, Boonyaroj et al. (2012) found that BPA rejection by a membrane covered with a layer of pollutant was $68.89 \%$, whereas rejection by a clean membrane was only $23.01 \%$.

In this study, membrane resistance $\left(R_{\mathrm{m}}\right)$ in each series was higher during filtration through the membrane with a lower cut-off (NF) (Table 1). It is not, however, obvious that $R_{\mathrm{m}}$ will be higher with NF than MF because a membrane with a higher cut-off is clogged mainly by pollutants that penetrate into the membrane pores. When the cut-off is lower, the membrane is clogged mainly by pollutants retained on its surface, and these pollutants could be removed by shearing forces if the filtration is performed in cross-flow mode, as in the present experiment.

In the current study, the composition of the feed solution affected the filtration process, as indicated by the positive correlations between BPA removal efficiency and membrane resistance $(R=0.83)$, and between BPA removal efficiency and the volumetric concentration factor $(\mathrm{VCF})$ $(R=0.64)$. Although the VCF increased when transmembrane pressure was increased from 0.3 to $0.7 \mathrm{MPa}$ $(R=0.68)$ (Table 1), this did not affect the retention of COD. At the highest initial BPA concentration, the permeability of the NF membrane was much lower than that of 
the MF membrane, as shown by the recovery value $(Y)$, which expresses the ratio of the permeate volume to the feed solution volume.

\section{Conclusion}

In conclusion, our results suggest that the use of ceramic $\mathrm{MF}$ and NF membranes is effective in post-treating biologically treated wastewater that contains BPA. At an initial BPA concentration of $0.3 \pm 0.14 \mathrm{mg} / \mathrm{L}$, BPA was completely removed. At higher BPA concentrations in the feed solution, from 61 to $75 \%$ of BPA was removed with NF. The efficiency of removal with MF was significantly lower (from 24 to $37 \%$ ). However, even at a membrane pore size of $0.45 \mu \mathrm{m}$, the MF membrane can remove BPA because it is sorbed on particulate matter, which is retained. Because the retentate from the membrane process contains a large BPA loading, further studies are necessary to find a solution for decontamination of the retentate by, for example, recirculating the retentate to a biological reactor.

Acknowledgments This work has been financed by the Polish National Science Center and statutory project. Thanks to Mark Leonard for proof-reading.

Open Access This article is distributed under the terms of the Creative Commons Attribution 4.0 International License (http:// creativecommons.org/licenses/by/4.0/), which permits unrestricted use, distribution, and reproduction in any medium, provided you give appropriate credit to the original author(s) and the source, provide a link to the Creative Commons license, and indicate if changes were made.

\section{References}

Agenson KO, Oh JI, Urase I (2003) Retention of a wide variety of organic pollutants by different nanofiltration/reverse osmosis membranes controlling parameters of process. J Membr Sci 225:91-103

Andrade LH, Mendes FDS, Espindola JC, Amaral MCS (2014) Nanofiltration as tertiary treatment for the reuse of dairy wastewater treated by membrane bioreactor. Sep Purif Technol 126:21-29

APHA Standard Methods for the Examination of Water and Wastewater (1992) 18th edn. APHA, AWWA and WEF, Washington

Bendick JA, Miller CJ, Kindle BJ, Shan H, Vidic RD, Neufeld RD (2005) Pilot scale demonstration of cross-flow ceramic membrane microfiltration for treatment of combined and sanitary sewer overflows. J Environ Eng 131:1532-1539
Bing-zhi D, Hua-qiang C, Lin W, Sheng-ji X, Nai-yun G (2010) The removal of bisphenol A by hollow fiber microfiltration membrane. Desalination 250:693-697

Bolong N, Ismail AF, Salim MR, Rana D, Matsuura T, TabeMohammadi A (2010) Negatively charged polyethersulfone hollow fiber nanofiltration membrane for the removal of bisphenol A from wastewater. Sep Purif Technol 73:92-99

Boonyaroj V, Chiemchaisri C, Chiemchaisri W, Theepharaksapan S, Yamamoto K (2012) Toxic organic micro-pollutants removal mechanisms in long-term operated membrane bioreactor treating municipal solid waste leachate. Bioresour Technol 113:174-180

Chen J, Huang X, Lee D (2008) Bisphenol A removal by a membrane bioreactor. Process Biochem 43:451-456

Escalona I, Fortuny A, Stüber F, Bengoa C, Fabregat A, Font J (2014) Fenton coupled with nanofiltration for elimination of bisphenol A. Desalination 345:77-84

Jin X, Hu J (2015) Role of water chemistry on estrone removal by nanofiltration with the presence of hydrophobic acids. Front Environ Sci Eng 9:164-170

Jin L, Ong SL, Ng HY (2010) Comparison of fouling characteristics in different pore-sized submerged ceramic membrane bioreactors. Water Res 44:5907-5918

Jung YJ, Kiso Y, Park HJ, Nishioka K, Min KS (2007) Rejection properties of NF membranes for alkylphenols. Desalination 202:278-285

Kasprzyk-Hordern B, Dinsdale RM, Guwy AJ (2009) The removal of pharmaceuticals, personal care products, endocrine disruptors and illicit drugs during wastewater treatment and its impact on the quality of receiving waters. Water Res 43:363-380

Kimura K, Toshima S, Amy G, Watanabe Y (2004) Rejection of neutral endocrine disrupting compounds (EDCs) and pharmaceutical active compounds (PhACs) by RO membranes. J Membr Sci 245:71-78

Lee WN, Kang IJ, Lee CK (2006) Factors affecting filtration characteristics in membrane coupled moving bed biofilm reactor. Water Res 40:1827-1835

Muthukumaran S, Nguyen DA, Baskaran K (2011) Performance evaluation of different ultrafiltration membranes for the reclamation and reuse of secondary effluent. Desalination 279:383-389

Nasu M, Goto M, Kato H, Oshima Y, Tanaka H (2001) Study on endocrine disrupting chemicals in wastewater treatment plants. Water Sci Technol 43:101-108

Nghiem LD, Vogel D, Khan S (2008) Characterising humic acid fouling of nanofiltration membranes using bisphenol $\mathrm{A}$ as a molecular indicator. Water Res 42:4049-4058

Schröder HF (2006) The elimination of the endocrine disrupters 4-nonylphenol and bisphenol A during wastewater treatmentcomparison of conventional and membrane assisted biological wastewater treatment followed by ozone treatment. Water Pract Technol. doi:10.2166/wpt.2006.060

Seyhi B, Drogui P, Buelna G, Blais JF (2012) Removal of bisphenolA from spiked synthetic effluents using an immersed membrane activated sludge process. Sep Purif Technol 87:101-109

Stringfellow WT, Alvarez-Cohen L (1999) Evaluating the relationship between the sorption of PAHs to bacterial biomass and biodegradation. Water Res 33:2535-2544

Sun X, Wang C, Li Y, Wang W, Wei J (2015) Treatment of phenolic wastewater by combined UF and NF/RO processes. Desalination 355:68-74 
Tanaka T, Yamada K, Tonosaki T, Konishi T, Goto H, Taniguchi M (2000) Enzymatic degradation of alkylphenols, bisphenol A, synthetic estrogen and phthalic ester. Water Sci Technol 42:89-95

Zahrim AY, Tizaoui C, Hilal N (2011) Coagulation with polymers for nanofiltration pretreatment of highly concentrated dyes: a review. Desalination 266:1-16

Zhang L, Feng X, Zhu N, Chen J (2007) Role of extracellular protein in the formation and stability of aerobic granules. Enzyme Microb Technol 41:551-557

Zheng X, Ernst M, Jekel M (2009) Identification and quantification of major organic foulants in treated domestic wastewater affecting filterability in dead-end ultrafiltration. Water Res 43:238-244
Zielińska M, Cydzik-Kwiatkowska A, Bernat K, Bułkowska K, Wojnowska-Baryła I (2014) Removal of bisphenol A (BPA) in a nitrifying system with immobilized biomass. Bioresour Technol 171:305-313

Zuehlke S, Duennbier U, Lesjean B, Gnirss R, Buisson H, Wasserbetriebe B, Water V (2003) Long term comparison of trace organics removal performances between conventional and membrane activated sludge processes. Proceedings of the 76th annual water environment federation technical exposition and conference. Los Angeles 